\title{
A VIOLÊNCIA CONTRAA MULHER COMO EXPRESSÃO DO PATRIARCADO E DO MACHISMO
}

\section{VIOLENCE AGAINST WOMEN AS EXPRESSION OF PATRIARCHY AND MALE CHAUVINISM}

\author{
Izabele Balbinotti ${ }^{1}$
}

RESUMO: Este artigo apresenta um estudo da influência da cultura patriarcal e do machismo na violência contra a mulher, numa perspectiva teórica. O trabalho percorre um caminho histórico da civilização explicando como a cultura matricêntrica deu lugar à patriarcal e como foram se estabelecendo os papéis masculinos e femininos na sociedade, aborda ainda a construção da ideologia do machismo e as correntes teóricas de dominação para explicar a violência contra a mulher. Por fim, apresenta a influência do patriarcado e do machismo na violência de gênero, mostrando que ainda hoje é no ambiente familiar que este tipo de violência se apresenta da forma mais persistente, atingindo a subjetividade feminina.

PALAVRAS-CHAVE: Patriarcado. Machismo. Violência contra a Mulher.
ABSTRACT: This article presents a study of the patriarchal culture and male chauvinism in violence against women from a theoretical perspective, the work traverses a historical path of civilization explaining how matricentric culture gave way to the patriarchal cultureand how they were establishing the male and female roles in society. It also brings the construction of the ideology of male chauvinism and the theoretical currents of domination to explain violence against women. Finally, it concludes there is an influence of patriarchy and male chauvinism on gender violence, showing that it is in family environment the most persistent form of violence, reaching female subjectivity.

KEYWORDS: Patriarchy. Male Chauvinism. Violence Against Women.

1 Advogada e jornalista, especialista em comunicação empresarial (Univali) e em marketing (INPG), pós-graduanda em direito público (Furb). Email: izabele_bv@ yahoo.com.br. 


\section{INTRODUÇÃO}

A violência de gênero se apresenta como uma expressão para fazer referência aos diversos atos praticados contra as mulheres como forma de submetê-las a sofrimento físico, sexual e psicológico, aí incluídas as diversas formas de ameaças. É caracterizada, especialmente, pela imposição ou pretensão de subordinação e controle do gênero masculino sobre o feminino.

Visando descortinar as origens desse fenômeno, este trabalho apresenta um estudo da influência da cultura patriarcal e do machismo na violência contra a mulher, numa perspectiva teórica. Para isso, foi dividido em três partes: a primeira expõe um caminho histórico da civilização explicando como a cultura matricêntrica, que tinha na mulher sua figura central, deu lugar à patriarcal e como foram se estabelecendo os papéis masculinos e femininos na sociedade; na segunda parte, relata a construção da ideologia do machismo e as correntes teóricas de dominação para explicar a violência contra a mulher e, por fim, na terceirta parte apresenta a influência do patriarcado e do machismo na violência de gênero.

Para tanto, a pesquisa foi realizada na perspectiva qualitativa, fundamentada na pesquisa bibliográfica.

\section{A VIRADA - DA CULTURA MATRICÊNTRICA PARA A PATRIARCAL}

Há cerca de dois milhões de anos, quando a espécie humana começou a habitar o planeta, as sociedades tinham como cultura a coleta e a caça de pequenos animais. Naquele tempo, não havia necessidade de força física para a sobrevivência e as mulheres possuíam um lugar central porque eram consideradas seres sagrados, capazes de dar a vida, ajudar na fertilidade da terra e dos animais. O masculino e o feminino governavam juntos. Havia divisão de trabalho entre os sexos, 
mas não desigualdade.

Enquanto as sociedades eram de coleta, as mulheres ocupavam um papel primordial para viabilizar a sobrevivência da espécie em condições hostis. Não havia coerção ou centralização, mas um rodízio de lideranças entre homens e mulheres. (MURARO, 2015).

Para Badinter (1986 apud TRAVASSOS, 2003), a separação de tarefas era a garantia da complementaridade entre os sexos e não de sua negação. Segundo a autora, ocorria uma dependência recíproca.

A prática da caça é responsável pelo desenvolvimento da inteligência nos homens, mas a prática da coleta pelas mulheres também requer habilidades, energia e inteligência, principalmente se for considerada a necessidade de dar, paralelamente, atenção aos filhos. Além disso, ambas as atividades exigem a socialização de seus participantes, que precisam aprender a cooperar com seus companheiros (as) de tarefa, para garantir a sobrevivência individual e do grupo. (BADINTER, 1986, p. 36-38 apud TRAVASSOS, 2003).

Muraro (2015) conta que nos grupos matricêntricos quase não existia guerra porque não havia pressão por conquista de novos territórios. Isso não acontecia nos locais onde a coleta era escassa e se iniciava a caça de grandes animais, quando a força física passou a se tornar essencial, marcando o início da supremacia masculina e da competividade entre os grupos em busca de novos territórios e de sobrevivência. Foi então que as guerras se tornaram constantes e os homens mais valorizados passaram a ser os heróis guerreiros. Começava a ruptura da harmonia entre homens e mulheres, mesmo que ainda não estivesse instalada a lei do mais forte.

No entanto, "[...] nem nas sociedades de coleta nem nas de caça se conhecia a função masculina na procriação." (MURARO, 2015, p.27). Quando o homem começou a entender sua 
função reprodutora, passou a controlar a sexualidade feminina. É neste tempo, com a sistematização da atividade agrária, a partir da invenção do arado, que a espécie humana deixou de ser nômade e surgiram as primeiras aldeias, depois as cidades, as Cidades-Estado, os primeiros Estados e os impérios. Segundo Stearns (2007, p. 31), “[...] o deslocamento da caça e da coleta para a agricultura pôs fim gradualmente a um sistema de considerável igualdade entre homens e mulheres". As sociedades, então, se tornam patriarcais, baseadas na supremacia do homem nas relações sociais.

Badinter (1986 apud TRAVASSOS, 2003) destaca que o patriarcado não se refere apenas a uma forma de família baseada no parentesco masculino e no poder paterno. O termo designa também toda estrutura social que nasça do poder do pai.

Para Millet e Scott, mencionadas por Narvaz e Koller (2006), o patriarcado é uma forma de organização social na qual as relações são regidas por dois princípios básicos: as mulheres estão hierarquicamente subordinadas aos homens e os jovens estão hierarquicamente subordinados aos homens mais velhos. De acordo com as autoras, a supremacia masculina atribuiu um maior valor às atividades masculinas em detrimento das atividades femininas, além de legitimar o controle da sexualidade, dos corpos e da autonomia feminina.

A partir daí, já não são mais os princípios feminino e masculino que governam juntos, mas vigora a lei do mais forte. As mulheres passam a ter sua sexualidade rigidamente controlada pelos homens e o casamento monogâmico traz a obrigação da mulher sair virgem das mãos do pai para o marido. Assim, a mulher fica reduzida ao âmbito doméstico e, como relata Muraro (2015, p.40):

Perde qualquer capacidade de decisão no domínio público, que se torna inteiramente reservado ao homem. A dicotomia entre o privado e o público estabelece, então, a origem 
da dependência econômica da mulher, e esta dependência, por sua vez, gera, no decorrer das gerações, uma submissão psicológica que dura até hoje.

Foi neste contexto que a cultura humana passou de matricêntrica a patriarcal, naturalizando processos socioculturais, como critica Saffioti (1979, p. 11): “[...] quando se afirma que é natural que a mulher se ocupe do espaço doméstico deixando livre para o homem o espaço público, está-se, rigorosamente, naturalizando um resultado da história". Esta naturalização, segundo a autora, constitui caminho mais fácil e curto para legitimar a 'superioridade' dos homens.

Assim, torna-se mais evidente o papel da mulher de forma secundária. Na Grécia, era reduzida às funções de mãe, prostituta ou cortesã. Tedeschi (2008 apud FARIAS, 2009, p.12), analisa "[...] a construção histórico-filosófica dos vários discursos que em certa época conferiram um caráter científico e natural aos papéis da mulher, do que significa ser mulher". Para tanto, o autor elegeu dois discursos fundamentais para a compreensão das primeiras representações construídas na história sobre o feminino: o discurso de matriz filosófica grega e o discurso da moral cristã no mundo medieval.

No discurso de matriz filosófica grega, o autor destaca o olhar masculino da teoria filosófica, que pensava a mulher como um objeto, ou seja, 'criaturas irracionais, sem pensar próprio', que deveriam viver sob o controle dos homens. Representações estas que, segundo o autor, é possível perceber no pensamento filósofo de Platão, Aristóteles e Hipócrates, que, por meio de um discurso masculino sobre o corpo feminino, construíram mitos que justificavam a inferioridade e a fragilidade feminina. Quanto às representações femininas presentes no discurso da moral católica, o autor ressalta que o modelo judaico-cristão exerceu influência significativa na definição do lugar ocupado pela mulher na igreja, na sociedade e na cultura ocidental, não restando dúvidas de que esse discurso foi fundamental para 
reforçar as desigualdades de gênero. (TEDESCHI, 2008, apud FARIAS, 2009, p. 12).

Em Roma, embora durante certo período tivessem liberdade sexual, as mulheres jamais chegaram a ter poder de decisão no Império. Do terceiro ao décimo século, eram jogadas ao domínio público quando havia escassez de homens por conta das guerras e voltavam ao domínio privado quando os homens reassumiam o seu lugar. Imperava uma persistente tradição intelectual que apontava a dicotomia homem/cultura e mulher/ natureza marcada por estereótipos, preconceitos e hierarquia de valores. Segundo Gonçalves (2006, p. 48-49), “[...] essa bipolaridade era sustentada pela ideia da 'desigualdade' entre os dois sexos, separando e opondo-os". Assim:

$\mathrm{O}$ universo masculino relacionado à cultura, sinônimo de objetivo, de racional e de público, determinava a sua dita 'superioridade' em relação ao universo feminino enquadrado à natureza 'reveladora' de sua suposta propensão ao emocional, ao subjetivo e ao privado. Não era de se estranhar, portanto, a predominância na narrativa histórica de preocupações com o político e com o público, as quais entronizavam os homens em suas façanhas e heroicidade, excluindo duplamente, quase que por completo, as mulheres enquanto personagens e produtoras da história. (GONÇALVES, 2006, p.48-49).

Às mulheres era reservado um lugar de menor destaque. Seus direitos e seus deveres estavam sempre voltados para a criação dos filhos e os cuidados do lar, portanto, para a vida privada. (SILVA, 2010).

$\mathrm{Na}$ alta Idade Média, as mulheres passaram a ter acesso às artes, às ciências e à literatura. E é logo depois dessa época, no período que vai do fim do século XIV até meados do século XVIII, que aconteceu a repressão sistemática do feminino, de forma generalizada na Europa, com os quatro séculos de 'caça às bruxas. (MURARO, 2015). 
Naquele tempo, as mulheres eram vistas especialmente por sua sensualidade e como ameaça ao poder médico, porque desde a mais remota antiguidade, eram as curadoras populares, as parteiras e em algumas tribos primitivas eram as xamãs. "Elas (as curadoras) eram as cultivadoras ancestrais das ervas que devolviam a saúde e eram também as melhores anatomistas do seu tempo." (MURARO, 2015, p.79-80). Eram também as parteiras e as médicas populares para todas as doenças.

Com o apoio da religião católica e depois da protestante, os tribunais da inquisição passaram a acusá-las, processá-las e julgá-las, condenando-as à morte na fogueira como bruxas. Segundo Muraro (2015), esse 'expurgo' visava recolocar dentro de regras de comportamento dominante as massas camponesas que se rebelavam e, principalmente, as mulheres, como um controle sobre o corpo e a sexualidade, como defende Foucault (1988). No mesmo sentido, Pinto (2010) conta que as mulheres que se rebelaram contra sua condição e que lutaram por liberdade, muitas vezes pagaram com suas próprias vidas: "A inquisição da igreja católica foi implacável com qualquer mulher que desafiasse os princípios por ela pregados como dogmas".

Já no século XVIII, quando cessou a caça às bruxas, houve grande transformação na condição feminina. A sexualidade se normatizou e as mulheres se tornaram frígidas. Também foram reduzidas exclusivamente ao âmbito doméstico, porque sua ambição era passível de castigo. O saber feminino popular caiu na clandestinidade e as mulheres não tinham mais acesso ao estudo como na idade média. Passaram então a transmitir voluntariamente aos filhos os valores patriarcais já totalmente interiorizados por elas e isso tem contribuído ainda hoje para a manutenção da cultura patriarcal, que visa "[...] manter a mulher no seu devido lugar." (MURARO, 2015, p.68).

Assim, a história mostra que as mulheres sempre estiveram presentes nas relações sociais, em diferentes espaços: de cen- 
tro da organização familiar a bruxas e, posteriormente, transmissoras de valores que buscam legitimar uma condição de inferioridade feminina.

\section{A CONSTRUÇÃO DA IDEOLOGIA DO MACHISMO}

Santos e Izumino (2005) apresentam três correntes teóricas utilizadas para explicar a violência contra a mulher. A primeira, chamada dominação masculina, defende a ideia de que a violência contra as mulheres é "[...] fruto da reprodução social de uma ideologia que transforma diferenças entre homens e mulheres em desigualdades hierárquicas autorizadoras da dominação e opressão da mulher." (BORGES; LUCCHESI, 2015, p. 226). Em outras palavras, a dominação da mulher ocorreria com a disseminação da ideologia na qual a condição feminina é definida como inferior à condição masculina, “[...] naturalizando uma superioridade do homem sobre a mulher e, consequentemente, a violência por ele perpetrada". (BORGES; LUCCHESI, 2015, p. 226).

Na segunda corrente, defendida por Saffioti (1979) tem-se a ideia de dominação patriarcal, fundada numa perspectiva feminista e marxista do patriarcado, a autora estuda a dominação masculina na sociedade de classes.

Pode-se dizer que esta corrente sustenta que o patriarcado não resume a dominação da mulher, a submissão da mulher ao 'poder do macho', à disseminação de uma ideologia machista, mas esta também é um instrumento importante de exploração econômica que tem como principal beneficiário o homem branco, rico e adulto. Neste sentido, a violência contra a mulher seria fruto desta socialização machista conservada pelo sistema capitalista, desta relação de poder desigual entre homens e mulheres, que estabelece como destino natural das mulheres a sua submissão e exploração pelos homens, forçando-as mui- 
tas vezes a reproduzir o comportamento machista violento. (SAFFIOTI, 1979, p. 150).

A terceira corrente tem como marco o trabalho de Gregori (1993), que buscou relativizar a relação dominação versus vitimização. Para a autora, "[...] existe alguma coisa que recorta a questão da violência contra a mulher que não está sendo considerada quando ela é lida apenas como ação criminosa e que exige punição." (GREGORI, 1993, p.166). Segundo ela, para entender a violência contra a mulher não se deve pressupor uma dualidade maniqueísta entre vítima e algoz, associados respectivamente a uma passividade e a uma ação destruidora.

A mulher vive de forma ambígua - ora gosta de ser indispensável e ora se ressente da limitação de sua liberdade. Aliás, é justamente esta situação paradoxal que explica ora a vitimização da mulher pela limitação de sua liberdade e pela possibilidade de seu corpo frágil sofrer violência, ora a manipulação que promove de seus medos para mostrar-se indispensável para o homem que pode ser o seu agressor, fazendo-o se sentir culpado e pronto para cumprir o papel por ela esperado. Deste modo, é possível constatar que as mulheres, muitas vezes inclusive por medo, reproduzem e reforçam os papéis de gênero, cooperando na produção de sua falta de autonomia, com o objetivo de obtenção de proteção e prazer. Neste contexto, a violência passa a funcionar perversamente como uma linguagem entre os parceiros que mantém a unidade do casal, a partir da preservação de seus papéis. (GREGORI, p. 1993, p.166).

A partir destas três correntes, torna-se fundamental discorrer sobre a força do machismo por trás do discurso de dominação. Autores como Arrazola e Rocha (1996) caracterizam o machismo como uma ideologia que determina que os homens controlem o mercado, o governo e a atividade pública e que as mulheres sejam subordinadas a eles, dividindo-os nos espaços público e privado.

O espaço público, dos homens, é o espaço social, que envol- 
ve educação, trabalho, política e literatura. Já o espaço privado, destinado às mulheres, é o espaço da produção e da sobrevivência doméstica e familiar. Segundo os autores, neste sentido, a cultura brasileira valida a esfera pública, social e econômica (masculina) e desvaloriza a esfera privada (feminina). No mesmo sentido, Souza, Baldwin e Rosa (2000, p. 08) defendem que os "[...] papéis de gênero condizem com interpretações tradicionais do Brasil como tendo uma cultura machista".

Ainda abordando os espaços, na dicotomia masculino-feminino, Andrade (2005) trabalha a divisão entre público e privado com correspondente divisão social do trabalho e os papéis diferenciados aos homens e mulheres, além de estereótipos.

A esfera pública, configurada como a esfera da produção material, centralizando as relações de propriedade, o trabalho produtivo (e a moral do trabalho) tem seu protagonismo reservado ao homem enquanto sujeito produtivo, mas não qualquer homem. A estereotipia correspondente para o desempenho deste papel (trabalhador de rua) é simbolizada no homem racional / ativo / forte / potente / guerreiro / viril / público / possuidor. A esfera privada, configurada, por sua vez, como a esfera da reprodução natural, e aparecendo como o lugar das relações familiares (casamento, sexualidade reprodutora, filiação e trabalho doméstico) tem seu protagonismo reservado à mulher, através do aprisionamento de sua sexualidade na função reprodutora e de seu trabalho no cuidado do lar e dos filhos. É precisamente este o eixo da dominação patriarcal. Os atributos necessários ao desempenho deste papel subordinado ou inferiorizado de esposa, mãe e trabalhadora do lar (doméstico), são exatamente bipolares em relação ao seu outro. A mulher é então construída femininamente como uma criatura emocional/ subjetiva/ passiva/ frágil/ impotente/ pacífica/ recatada/ doméstica/ possuída. (ANDRADE, 2005, p.14-15).

A concepção do masculino como sujeito da sexualidade e do feminino como seu objeto é um valor de longa duração da cultura ocidental. Com base no patriarcalismo, o masculino é visto 
como o lugar da ação, da decisão, da chefia da rede de relações familiares e da paternidade. Da mesma forma, o masculino é investido na posição social de agente do poder da violência, havendo, historicamente, uma relação direta entre as concepções vigentes de masculinidade e o exercício do domínio de pessoas, das guerras e das conquistas, como relata Stearns (2007, p. 34):

A força do patriarcado caiu sobre as mulheres, mas obviamente afetou também as definições de masculinidade. Os homens, independentemente da personalidade de cada um, deveriam assumir seus papéis de dominantes. Deviam evitar mimar as mulheres, especialmente em público. Com frequência, precisavam estar prontos a assumir deveres militares ou outro tipo de liderança e, em princípio, eram evidentemente responsáveis pela sobrevivência da família.

Relacionando as formas de viver a masculinidade e a cultura da violência, Minayo(2005) utiliza como referência Machado (2001) em sua pesquisa antropológica que teve como parâmetro a análise de valores de longa duração que estruturam a cultura ocidental patriarcal. Machado (2001) trabalha o discurso e a performance de grupo de delinquentes sociais apenados, nos quais a autora encontra de forma aguçada as características da cultura machista. Especificamente nas relações conjugais, a prática cultural considera normal o masculino como a posição do 'macho social', com atitudes e relações violentas justificadas como 'atos corretivos'.

Por isso, em geral, quando acusados, os agressores reconhecem apenas 'seus excessos' e não sua função disciplinar da qual se investem em nome de um poder e de uma lei que julgam encarnar. Geralmente quando narram seus comportamentos violentos, os maridos (ou parceiros) costumam dizer que primeiro buscam 'avisar', 'conversar' e depois, se não são obedecidos, 'batem'. Consideram, portanto, que as atitudes e ações de suas mulheres (e por extensão, de suas filhas) estão sempre distantes do comportamento ideal do qual se julgam guardiões e precisam garantir e controlar. (MINAYO, 2005). 
No mesmo sentido, Borges e Lucchesi (2015) apontam a violência como a expressão mais evidente da dominação masculina. Para os autores, a violência representa o ponto culminante da afirmação da virilidade, como forma de expressão da superioridade do homem "[...] no discurso da construção social dos sexos, o que não é muito tolerado, já que denuncia o assujeitamento feminino e desta maneira coloca em risco a manutenção da ordem masculina". (BORGES; LUCCHESI, 2015, p. 234). Como na sociedade romana, "[...] o marido é o juiz da esposa. Se ela comete uma falta, ele a pune, se ela bebeu vinho, ele a condena, se ela cometeu adultério, ele a mata" (STEARNS, 2007, p. 38). Este comportamento tem se repetido ao longo da história, como aponta Blay (2003, p. 87):

Agredir, matar, estuprar uma mulher ou uma menina são fatos que têm acontecido ao longo da história em praticamente todos os países ditos civilizados e dotados dos mais diferentes regimes econômicos e políticos. A magnitude da agressão, porém, varia. É mais frequente em países de uma prevalecente cultura masculina, e menor em culturas que buscam soluções igualitárias para as diferenças de gênero.

Desta forma, a mentalidade patriarcal, que preconiza o controle das mulheres e a rivalidade entre homens, está sempre presente nas agressões por ciúme, refletindo o medo da perda do objeto sexual e social.

Independente da corrente teórica que busque explicar as raízes da violência contra a mulher, mostra-se evidente que o machismo vai muito além de uma conduta construída, aprendida e reforçada culturalmente a partir de definições de papéis de gênero. Como defende Foucault (1988), cada cultura constrói discursos específicos de masculinidade, por meio de ideologias masculinas pela fala, mídia, música e literatura popular, e também pela lei. 


\section{A VIOLÊNCIA DE GÊNERO COMO EXPRESSÃO DO PATRIARCADO E DO MACHISMO}

Para abordar a violência torna-se fundamental discorrer acerca da sua relação com o poder. E é nas palavras de Arendt $(2009$, p. 73$)$ a que se recorre analogicamente ${ }^{2}$ : “[...] onde um domina absolutamente, o outro está ausente. A violência aparece onde o poder está em risco, mas, deixada a seu próprio curso, conduz à desaparição do poder".

Nesse sentido, Guimarães e Pedrosa (2017) ressaltam que uma ação violenta está direcionada à destruição ou ao ataque da subjetividade do outro e surge no momento em que o sujeito sente que está perdendo seu poder ou se depara com sua impotência. Nesta linha, a violência funciona como uma interposição à subjetividade, uma forma de impor coerções ao corpo com o objetivo de atingir a subjetividade, a afetividade e o pensamento daquele que sofre a violência.

Em suas pesquisas, as autoras citam estudos ${ }^{3}$ que têm demonstrado o quanto, de fato, os valores culturais machistas e patriarcais estruturantes estão associados à grave recorrência de violência contra as mulheres e às sérias desigualdades de poder e de direitos enfrentados por elas.

Como trazem Narvaz e Koller (2006), ainda que não se possa reduzir ao patriarcado a explicação de todas as formas de desigualdades e de opressão do gênero feminino, a violên-

2 Disse-se analogicamente porque Arendt aborda em sua obra "Sobre a violência" o poder sob a ótica da política. No entanto, pode-se aplicar em outros enfoques, como se faz aqui.

3 CHAUÍ, Marilena. Ética, política e violência. In Ensaios sobre violência. Vitória: Edufes, 2003.;DINIZ, Gláucia Ribeiro Starling; ANGELIM, Fábio Pereira. Violência doméstica: porque é tão difícil lidar com ela? Revista de Psicologia da Unesp; MACHADO, Lia Zanotta. Perspectivas em confronto: relações de gênero ou patriarcado contemporâneo? Série Antropologia, 2000; SAFFIOTTI, Heleieth. Já se mete a colher em briga de marido e mulher. São Paulo em Perspectiva. Revista da Fundação Seade. 
cia contra as mulheres tem ali seu nascedouro, como sustentam correntes feministas.

Oliveira (2012) se apoia nesta ideia e defende que a origem da subordinação feminina foi firmada a partir de um determinismo biológico, assim como das construções sociais e econômicas do sistema patriarcal, que definiram a mulher como 'o outro', construindo, como acentua Beauvoir (1980), uma realidade feminina sob um ponto de vista masculino.

Segundo Alves e Cavenagui (2000), estamos diante de um simbolismo de gênero com sua poderosa estereotipia e carga estigmatizante.

Este simbolismo (enraizado nas estruturas) que homens e mulheres, no entanto, reproduzem, apresenta a polaridade de valores culturais e históricos como se fossem diferenças naturais (biologicamente determinadas) e as pessoas do sexo feminino como membros de um gênero subordinado, na medida em que determinadas qualidades, bem como o acesso a certos papéis e esferas (da Política, da Economia e da Justiça, por exemplo) são percebidos como naturalmente ligados a um sexo biológico e não ao outro. De tal maneira que a mulher é construída como (não) sujeito do gênero feminino. (ALVES; VAVENAGUI, 2000, p.11).

Millett (1975) também ressalta os estereótipos comportamentais atribuídos a cada categoria sexual, justificados pela experiência biológica. Para a autora, tanto o homem quanto a mulher seguem um código de conduta que determina gestos, atitudes e papeis sociais determinados.

O temperamento se desenvolve de acordo com certos estereótipos característicos de cada categoria sexual (a masculina e a feminina), baseados nas necessidades e nos valores do grupo dominante e ditados por seus membros em função do que mais apreciam em si mesmos e do que mais convém exigir de seus subordinados: a agressividade, a inteligência, a força e a eficácia, no macho; a passivida- 
de, a ignorância, a docilidade, a 'virtude' e a inutilidade na fêmea. Este esquema fica reforçado por um segundo fator, o papel sexual, que decreta para cada sexo um código de conduta, gestos e atitudes altamente elaborado. No terreno da atividade, para a mulher é atribuído o serviço doméstico e o cuidado com a prole, enquanto que o macho pode ver realizados seus interesses e ambições em todos os demais campos da produtividade humana. O restrito papel que se atribui à mulher tende a frear o seu progresso no nível da experiência biológica. (MILLET, 1975, p.35, tradução nossa).

Neste ponto, no final da década de 1960, o feminismo começa a lançar ideias para desconstruir os mitos criados e descrever, sob o ponto de vista das mulheres, o mundo que lhes fora proposto. Segundo Beauvoir (1980), o destino da mulher não estaria definido por nenhum desses elementos senão pela construção social:

Ninguém nasce mulher, torna-se mulher. Nenhum destino biológico, psíquico, econômico define a forma que a fêmea humana assume no seio da sociedade; é o conjunto da civilização que elabora esse produto intermediário entre o macho e o castrado que qualificam de feminino. (BEAUVOIR, 1980, p. 9).

Neste contexto, a autoridade familiar e doméstica, além de ser responsável pela fundação do patriarcado, implica em uma divisão sexual, considerada natural. Mas segundo Machado (2012), “[...] o objetivo é exatamente o contrário. É desnaturalizá-lo, mostrando o seu engendramento social e cultural como um 'sistema' ou como uma forma de 'dominação", onde as diversas formas de discriminação e de violência contra as mulheres são manifestação de relações de poder conhecidas pela expressão violência de gênero, que tem no componente cultural seu grande sustentáculo.

Guimarães e Pedrosa (2017) contam que o conceito de gê- 
nero foi proposto por estudiosas feministas americanas como Stoller e Gayle Rubin, na década de 70, como objeto de estudo. A proposta buscava superar o determinismo biológico relacionado ao uso do termo sexo ou diferenciação sexual e destacar a construção social das identidades de homens e mulheres, desconstruindo definições e papéis referentes ao masculino e ao feminino.

Na perspectiva pós-moderna, os estudos de gênero trouxeram uma nova problemática: repensar as categorias de identidade de gênero e as associações entre determinismo biológico e diferenciação sexual. Silveira e Nardi (2014) elegeram estudiosas feministas como Joan Scott e Judith Butler para compreender o gênero de forma complexa, aberto a múltiplas interpretações, não limitado à lógica do patriarcado.

Segundo Butler (2012, p. 24), gênero foi inicialmente compreendido como "[...] os significados culturais assumidos pelo corpo sexuado", produzindo uma separação entre sexo, relacionado à biologia, e gênero, definido pela cultura. A autora critica a dissociação feita pelos movimentos feministas entre cultura e sexo, como se a primeira fosse simplesmente uma inscrição cultural e o segundo, biológico. Defende que tanto o sexo não pode ser reduzido a uma característica anatômica, por ser também uma construção simbólica; como o gênero não pode ser reduzido a formulações fixas da cultura - "[...] nesse caso, não a biologia, mas a cultura se torna o destino." (BUTLER, 2012, p. 26). Já Scott afirmava que o gênero era o primeiro exercício de poder sobre os corpos. (SILVEIRA; NARDI, 2014).

Mas como esse exercício de poder não era o único, Silveira e Nardi (2014) contam que "[...] logo emergiram proposições teóricas que sustentaram a existência de três grandes marcadores sociais que atravessam a produção de subjetividade: a 
classe, o gênero e a raça”. Neste sentido, Saffioti (2009), diz que mais do que papéis sociais que se aprendem nos processos de socialização, são as identidades sociais, como o gênero, a raça, a etnia e a classe que vão alimentando a subordinação, a partir das experiências vividas.

Vale ressaltar que, ao se acolher as expressões de dominação-exploração, utilizadas de forma alternada, mas sempre juntas, como entendia Safiotti (2009), elas não significam pura submissão, mas estão ligadas a relações de poder na perspectiva de Foucault. Para ele, as relações de poder constituem "[...] o campo de possibilidades dos modos de subjetivação no interior dos quais se articulam os processos de resistência." (SILVEIRA; NARDI, 2014), ou seja, neste campo de possibilidades há jogos de verdade que potencializam determinadas formas do ser humano se constituir como sujeito.

Quando se fala em dominação, vale destacar sua presença na relação entre família e patriarcado. Narvaz e Koller (2006) apontam que a associação entre estes dois termos remete à origem do termo 'família', consolidado na Roma Antiga, oriundo do vocábulo latino famulus, que significa «escravo doméstico». Conforme relata Xavier (1998), a família romana era centrada no homem, já que o patriarca tinha sob seu poder a mulher, os filhos, os escravos e os vassalos, além do direito de vida e de morte sobre todos eles.

Segundo Saffioti (1979), no Brasil a história da instituição familiar teve como ponto de partida o modelo patriarcal, importado pela colonização e adaptado às condições sociais de país latifundiário e escravagista. Na mesma linha, Chauí (1985) aponta que apesar da desintegração do patriarcado rural, que ocorreu de forma diferenciada em diversas regiões do Brasil, a mentalidade patriarcal permaneceu na vida e na política brasileira e também no meio urbano, como uma forma de 
dominação sobre a condição feminina.

Nesta perspectiva, a posição da mulher, na família e na sociedade em geral, desde a colonização até hoje, demonstra que o patriarcado foi uma das matrizes da organização social brasileira.

No Brasil Colônia, o que se constata é que o homem é o chefe da casa e da família, é o líder da sociedade conjugal e é ele quem domina a esposa e os filhos, nos mesmos moldes da família romana. Dentro deste contexto, apenas o homem da família possuía direitos e cidadania plena. Na visão de Ruzyk (2005, p.119), nessa sociedade colonial, "a esposa tem papel definido nesta estrutura familiar, como de subordinação, papel este para o qual é criada desde a mais tenra infância".

Como defende Andrade (2005), o mecanismo de controle dirigido às mulheres, enquanto operadoras de papéis femininos na esfera privada tem sido nuclearmente o controle informal materializado na família (pais, padrastos, maridos, dele também coparticipando a escola, a religião e a moral) e, paradoxalmente, a violência contra a mulher (crianças, jovens e adultas), dos maus-tratos à violação e o homicídio.

Nas palavras de Oliveira (2012), na lógica patriarcal, existem alguns modelos comportamentais que devem ser compulsoriamente observados: "[...] a virilidade e a honra como marcadores da identidade masculina; a docilidade e a submissão caracterizando a identidade feminina". Esta ideologia aponta para uma posição de superioridade dos machos em relação às fêmeas da espécie humana, segundo o autor, fazendo surgir a violência com a justificativa do gênero, que legitima a agressão, a mutilação e, em casos mais extremos, a morte por maridos, companheiros ou pais.

Esta ideologia tem representado o modelo dominante da família brasileira, sendo que o Estado, também como uma 
expressão do patriarcalismo, somente passou a intervir nas relações privadas (da família) em tempos recentes. Em 1916, o Código Civil Brasileiro dispunha que a mulher casada só poderia trabalhar com a autorização do marido. Em 1934, uma nova constituição assegurou o voto da mulher. O trabalho feminino foi regulamentado pela Consolidação das Leis do Trabalho somente em 1941.

Durante a ditadura Vargas, os movimentos feministas foram reprimidos, sendo retomados novamente no início da Segunda Guerra Mundial.

Nesta época, nos países desenvolvidos, os homens foram para o front de batalha e as mulheres tiveram que trabalhar para sustentar suas famílias. O Estado de Bem-Estar Social, característico do pós-Segunda Guerra, em 1945, girava em torno do pleno emprego masculino e propunha o cuidado feminino do lar. A mulher, beneficiária do suporte social assegurado pelo trabalho masculino, não dispunha das mesmas garantias, a não ser enquanto esposa ou filha, o que evidenciava sua condição de dependente do marido/pai. Percebida apenas como uma coadjuvante no sustento da família, não sua mantenedora. (NARVAZ; KOLLER, 2006).

Somente em 1962 o Código Civil Brasileiro permitiu que mulheres casadas pudessem trabalhar sem a autorização de seus maridos e foi com a Constituição Federal de 1988 e com o Código Civil de 2002, que alguns direitos femininos já incipientes foram consolidados. A família não seria mais regida pelo pátrio poder, ou seja, pelo poder do pai, como na época feudal, mas pelo poder familiar, que pressupõe a igualdade de poder entre os membros do casal. Na Constituição, o princípio da igualdade entre homens e mulheres vem expresso no artigo $5^{\circ}$, que trata dos direitos e garantias fundamentais.

Para Pateman (1993, p. 167), existe um patriarcado moderno, contratual, que estrutura a sociedade civil capitalista 
e mantém as premissas do pensamento patriarcal tradicional. Uma vez mantido o direito natural conjugal dos homens sobre as mulheres, como se cada homem tivesse o direito natural de poder sobre a esposa, há um patriarcado moderno. E este patriarcado muitas vezes se reflete em violência de gênero, que, conforme Souza (2007, p. 35):

[...] se apresenta como uma forma mais extensa e se generalizou como uma expressão utilizada para fazer referência aos diversos atos praticados contra as mulheres como forma de submetê-las a sofrimento físico, sexual e psicológico, aí incluídas as diversas formas de ameaças, não só no âmbito intrafamiliar, mas também abrangendo a sua participação social em geral, com ênfase para as suas relações de trabalho, caracterizando-se principalmente pela imposição ou pretensão de imposição de uma subordinação e controle do gênero masculino sobre o feminino. A violência de gênero se apresenta, assim, como um 'gênero', do qual as demais são espécies.

$\mathrm{Na}$ definição do Conselho Nacional de Justiça, violência de gênero é a "[...] violência sofrida pelo fato de ser mulher, sem distinção de raça, classe social, religião, idade ou qualquer outra condição, produto de um sistema social que subordina o sexo feminino". (BRASIL, CNJ - CONSELHO NACIONAL DE JUSTIÇA. FORMAS DE VIOLÊNCIA). Soihet (2005) vai além e faz referência ao conceito de violência simbólica ao examinar a violência nas relações de gênero:

Exaltado como expressão de beleza, inspirador do desejo fonte de prazer, de vida - através da maternidade -, símbolo da nação republicana - na França pós-revolucionária, como no Brasil - o corpo feminino é também lugar de violência, seja a violência física - espancamentos, estupros etc. - tão bem conhecida, sejam aquelas outras formas de violências sutis, engenhosas, entre as quais a violência simbólica, que igualmente, contribui para a manutenção das desigualdades. (SOIHET, 2005, p. 305). 
No mesmo sentido, Chartier (1995, p. 42) defende que reconhecer a dimensão da violência doméstica "[...] ajuda a compreender como a relação de dominação, que é uma relação histórica, cultural e linguisticamente construída, é sempre afirmada como uma diferença de natureza radical, irredutível, universal".

É, portanto, no seio familiar, que muitas vezes a violência de gênero se apresenta da forma mais cruel e persistente, sustentada por valores culturais machistas e patriarcais, que 'justificam' comportamentos de dominação, poder e grande interferência na subjetividade feminina.

\section{CONCLUSÃO}

Com o objetivo de trazer ideias sobre as bases da violência de gênero, evidentemente sem esgotar o assunto, esse trabalho apresentou um estudo da influência da cultura patriarcal e do machismo na violência contra a mulher, numa perspectiva teórica.

Ao percorrer um caminho histórico da civilização, verificou-se que, no início das relações sociais, as mulheres eram consideradas seres sagrados e havia divisão de trabalho entre homens e mulheres, mas não desigualdades baseadas na força física. Com a escassez da coleta e a partida para a caça de grandes animais, a força masculina começou a ganhar evidência, mas foi com o desenvolvimento da agricultura que iniciou a supremacia masculina.

As sociedades se tornaram patriarcais e as mulheres e os mais jovens passaram a ser subordinados ao "poder do pai". Com o controle da sexualidade feminina, as mulheres passaram a ficar restritas ao domínio privado e aos homens ficou reservado o domínio público.

No âmbito privado, a mulher passou a alimentar um sistema 
de dependência, controle e violência. Já o homem fortaleceu o sistema de dominação, com a busca por poder, competitividade e violência. Cada vez mais a desigualdade entre homens e mulheres era sustentada por estereótipos, preconceitos e hierarquias de valores.

Após uma incursão feminina no conhecimento, com acesso às artes, às ciências e à literatura e posteriormente uma "caça às bruxas" na alta idade média, a mulher voltou ao espaço privado e passou a transmitir aos filhos os valores patriarcais que a subjugavam.

Neste contexto, também foi importante estudar a construção da ideologia do machismo por trás do discurso de dominação, a partir de três correntes teóricas: a corrente de dominação masculina (crença em desigualdades hierárquicas, que autorizam a opressão da mulher porque a condição feminina é inferior), a de dominação patriarcal (exploração econômica que beneficia o homem branco, rico e adulto) e a de dominação versus vitimização (mulheres reproduzindo e reforçando os papéis de gênero, se colocando em posição de fragilidade).

Pelo estudo, fica evidente a força do machismo por trás do discurso de dominação, onde os homens controlam os espaços públicos (educação, trabalho e política, por exemplo) e às mulheres resta o espaço privado (unidade doméstica). Ao homem ficam atribuídas as características de força, virilidade, posse e autoridade e à mulher: emoção, passividade, fragilidade e submissão.

Com os homens assumindo papéis dominantes e buscando serobedecidos, a violência se mostra como a expressão mais evidente da dominação masculina, como uma afirmação da virilidade e da superioridade do homem diante da mulher. A ação violenta como ataque ao outro surge como uma reação quando o sujeito homem sente que está perdendo seu poder ou se de- 
para com sua impotência.

Neste contexto, as correntes feministas contestam o determinismo biológico e afirmam que a posição da mulher depende da construção social, assim como as diversas formas de violência contra ela são manifestação de relações de poder sustentadas pela cultura.

Em síntese, restou demonstrado que a violência de gênero é expressão do patriarcado e do machismo, visto que os valores culturais estão associados às desigualdades e a violência instaura a 'naturalidade' das diferenças, com estereótipos e códigos de conduta entre homens e mulheres. Fica, portanto, evidente que é no ambiente familiar que a violência de gênero se apresenta da forma mais persistente, atingindo a subjetividade feminina.

\section{REFERÊNCIAS}

ALVES, José Eustáquio Diniz; CAVENAGUI, Suzana. Dominação masculina e discurso sexista. Informe ANDES, ano XI, n. 97, fev. 2000.

ANDRADE, Vera Regina Pereira de. A soberania patriarcal: o sistema de justiça criminal no tratamento da violência sexual contra a mulher. In: Revista Seqüência, n. 50, p. 71-102, jul. 2005. Disponível em: <http://www.cnj.jus.br/files/conteudo/arquivo/2016/02/4f33baebd636cb77eb9a4bdc2036292c.pdf>. Acesso em: 23 maio 2018.

ARENDT, Hanna. Sobre a violência. Rio de Janeiro: Civilização Brasileira, 2009.

ARRAZOLA, Laura Duque; ROCHA, Irene. Mulher, natureza, cultura: apontamentos para um debate. In: G. RABAY (Org.). Mulheres e sociedade. João Pessoa: UFPB/ Editora Universitária, 1996.

BADINTER, Elisabeth. Um é o outro. Rio de Janeiro: Nova Fronteira, 1986 apud TRAVASSOS, Eliane. Mulher, história e psicanálise. Dissertação de Mestrado em Psicologia. Centro de Filosofia e Ciências Humanas. Universidade Federal de Santa Catarina. 2003. Disponível em: $<$ https://repositorio.ufsc.br/xmlui/bitstream/handle/123456789/85967/190642.pdf;jsessionid=1DF390F664D40C8AFCE89EAEAAA2D984? sequence $=1>$. Acesso em: 23 maio 2018.

BEAUVOIR, Simone de. O Segundo sexo. Rio de Janeiro: Nova Fronteira, 1980.

BLAY, Eva Alterman. Violência contra a mulher e politicas públicas. In: Revista Estudos Avançados. [online]. v,17, n.49, p. 87-98. 2003. Disponível em: <http://dx.doi. org/10.1590/S0103-40142003000300006>. Acesso em: 23 maio 2018.

BORGES, Clara Maria Roman; LUCCHESI, Guilherme Brenner. O machismo no banco dos réus: uma análise feminista crítica da política criminal brasileira de combate à 
violência contra a mulher. In: Revista da Faculdade de Direito - Universidade Federal do Paraná, Curitiba, v. 60, n. 3, set./dez. 2015. Disponível em: $<$ http://revistas.ufpr.br/ direito/article/view/41788/26948>. Acesso em: 23 maio 2018.

BUTLER, Judith. Problemas de gênero: feminismo e subversão da identidade. 4. ed. Rio de Janeiro: Civilização Brasileira. 2012.

CHARTIER, Roger. Diferenças entre os sexos e dominação simbólica (nota crítica). Cadernos Pagu: fazendo história das mulheres. Campinas, Núcleo de Estudos de Gênero, Universidade Estadual de Campinas (Unicamp), n.4, 1995.

CHAUÍ, Marilena. Participando do debate sobre mulher e violência. In: CHAUÍ, Marilena; CARDOSO, Ruth; PAOLI, Maria Celia (Org.). Perspectivas antropológicas da mulher: sobre mulher e violência. Rio de Janeiro: Zahar, 1985.

CNJ. Formas de violência. Disponível em: <http:/www.cnj.jus.br/programas-e-acoes/ lei-maria-da-penha/formas-de-violencia>. Acesso em: 23 maio 2018.

FOUCAULT, Michel. História da sexualidade I: a vontade de saber. Rio de Janeiro: Edições Graal, 1988.

GONÇALVES, Andréa Lisly. História \& gênero. Belo Horizonte: Autêntica, 2006, p.48-49 apud GOMES, Gisele Ambrósio. História, mulher e gênero. Disponível em: <http://www.ufjf.br/virtu/files/2011/09/HIST\%C3\%93RIA-MULHER-E-G\%C3\%8ANERO.pdf $>$. Acesso em: 23 maio 2018.

GREGORI, Maria Filomena. Cenas e queixas: um estudo sobre mulheres, relações violentas e a prática feminista. São Paulo: ANPOCS, 1993.

GUIMARÃES, Maisa Campos; PEDROZA, Regina Lucia Sucupira. Violência contra a mulher: problematizando questões teóricas, filosóficas e jurídicas. Disponível em: $\quad<\mathrm{http} / /$ www.scielo.br/scielo.php?script=sci_arttext\&pi$\mathrm{d}=\mathrm{S} 0102-71822015000200256 \& \operatorname{lng}=\mathrm{en} \& \mathrm{nrm}=\mathrm{iso \& t} \mathrm{lng}=\mathrm{pt}>$. Acesso em: 23 maio 2018.

IZUMINO, WâniaPasinato; SANTOS, Cecília Macdowell. Violência contra as mulheres e violência de gênero no Brasil. In: Revista Estudios Interdisciplinários de America Latina y El Caribe. Israel: Universidade de TelAviv, v. 1, n. 16, 2005. Disponível em: $<$ http://www.nevusp.org/downloads/down083.pdf>. Acesso em: 23 maio 2018.

MACHADO, Lia Zanotta. Perspectivas em confronto: relações de gênero ou patriarcado contemporâneo? UNB, Departamento de Antropologia - DAN (Série Antropologia) apud OLIVEIRA, Anderson Eduardo Carvalho de. Atendimento a homens autores de violência contra a mulher: lacunas, desafios e perspectivas. Dissertação de Mestrado - Universidade Federal da Bahia. 2012. Disponível em: $<$ https://repositorio.ufba.br/ri/bitstream/ri/7778/1/Disserta\%C3\%A7\%C3\%A3o\%20 Mestrado\%20-\%20Anderson\%20Eduardo\%20Carvalho\%20de\%20Oliveira.pdf>. Acesso em: 23 maio 2018.

. Masculinidades e violências: Gênero e mal-estar na sociedade contemporânea. Série Antropológica. Brasília: UNB, 2001.

MILLETT, Kate. Teoria de la política sexual. In: Política sexual. México: DF, 1975.

MINAYO, Maria Cecilia de Souza. Laços perigosos entre machismo e violência. In: Ciênc. saúde coletiva. v.10, n.1, Rio de Janeiro. jan./mar. 2005. Disponível em: $<$ http:// www.scielo.br/scielo.php?script=sci_arttext\&pid=S1413-81232005000100005>. 
Acesso em: 23 maio 2018.

MURARO, Rose Marie. Introdução. In: KRAEMER, Heinrich; SPRENGE, James. $O$ martelo das feiticeiras. Rio de Janeiro: BestBolso, 2015.

NARVAZ, Martha Giudice; KOLLER, Sílvia Helena. Famílias e patriarcado: da prescrição normativa à subversão criativa. In: Psicol. Soc. v.18, n.1. Porto Alegre. jan/ abr. 2006. Disponível em: <http://dx.doi.org/10.1590/S0102-71822006000100007>. Acesso em: 23 maio 2018.

OLIVEIRA, Anderson Eduardo Carvalho de. Atendimento a homens autores de violência contra a mulher: lacunas, desafios e perspectivas. Dissertação de Mestrado - Universidade Federal da Bahia. 2012. Disponível em: <https://repositorio.ufba.br/ri/bitstream/ri/7778/1/Disserta\%C3\%A7\%C3\%A30\%20Mestrado\%20-\%20Anderson \%20 Eduardo\%20Carvalho\%20de\%20Oliveira.pdf>. Acesso em23 de maio de 2018.

PATEMAN, Carole. O contrato sexual. Rio de Janeiro: Paz e Terra, 1993.

PINTO, Céli Regina Jardim. Feminismo, história e poder. In: Rev. Sociol. Polít. v.18, n. 36. Curitiba. Jun. 2010. Disponível em: <http://dx.doi.org/10.1590/S010444782010000200003>. Acesso em: 23 maio 2018.

RUZYK, Carlos Eduardo Pianovski. Famílias simultâneas: da unidade codificada à pluralidade constitucional. Rio de Janeiro: Renovar, 2005.

SAFFIOTI, Heleieth. A mulher na sociedade de classes: mitos e realidade. Rio de Janeiro: Rocco, 1979.

. Ontogênese e filogênese do gênero: ordem patriarcal de gênero e a violência masculina contra mulheres. Série Estudos/Ciências Sociais/FLASCO-Brasil. 2009. Disponível em: <http://flacso.redelivre.org.br/files/2015/03/Heleieth_Saffioti.pdf $>$. Acesso em: 22 maio 2018.

SILVA, Sérgio Gomes da. Preconceito e discriminação: as bases da violência contra a mulher. In: Psicologia ciênc. prof. Brasília, v. 30, n.3. set. 2010. Disponível em: <http:// dx.doi.org/10.1590/S1414-98932010000300009>. Acesso em: 23 de maio de 2018.

SILVEIRA, Raquel da Silva; NARDI, Henrique Caetano. Interseccionalidade gênero, raça e etnia e a lei Maria da Penha. 2014. Disponível em: <http://www.scielo.br/pdf/ psoc/v26nspe/03.pdf>. Acesso em: 23 maio 2018.

SOIHET, Rachel. Corpo feminino e formas de violência: discursos e práticas. In: SWAIN, Tania Navarro; MUNIZ, Diva do Couto Gontijo (Orgs). Mulheres em ação: práticas discursivas e práticas políticas. Florianópolis: Mulheres; Belo Horizonte: PUC Minas, 2005.

SOUZA, Eros de; BALDWIN, John; ROSA, Francisco Heitor da. A construção social dos papéis sexuais femininos. In: Psicol. Reflex. Crit. Porto Alegre, v.13, n. 3. 2000. Disponível em: <http://dx.doi.org/10.1590/S0102-79722000000300016>. Acesso em: 23 maio 2018.

SOUZA, Sérgio Ricardo de. Comentários à lei de combate à violência contra a mulher. 22. ed. Curitiba: Juruá, 2007.

STEARNS, Peter. História das relações de gênero. São Paulo: Contexto, 2007.

TEDESCHI, Losandro Antônio. História das mulheres e as representações do femi- 
nino. Campinas: Curt Nimuendajú, 2008 apud FARIAS, Marcilene Nascimento de. $A$ história das mulheres e as representações do feminino na história. Estudos Feministas. Florianópolis. Set./Dez. 2009.

XAVIER, Elodia. Declínio do patriarcado: a família no imaginário feminino. Rio de Janeiro: Record, Rosa dos Tempos, 1998.

Recebido em: 29/05/2018
Aprovado em: 15/08/2018 